\title{
Atribut Penilaian Keberlanjutan Pengelolaan Lingkungan Rumah Sakit Menuju Green Hospital di Indonesia
}

\author{
Sutanto $^{1^{*}}$, Eka Intan Kumala Putri ${ }^{2}$, Bambang Pramudya $^{3}$, Suyud Warno Utomo ${ }^{4}$ \\ ${ }^{1}$ Mahasiswa Sekolah Pascasarjana, Program Studi Pengelolaan Sumberdaya Alam dan Lingkungan, Institut Pertanian Bogor, \\ Baranangsiang Bogor, Jawa Barat. \\ 2 Departemen Ekonomi Sumberdaya Lingkungan, Fakultas Ekonomi dan Manajemen, Institut Pertanian Bogor, Dramaga, \\ Bogor, Jawa Barat. \\ 3 Departemen Teknologi Industri Pertanian, Fakultas Pertanian, Institut Pertanian Bogor, Dramaga, Bogor, Jawa Barat. \\ 4 Departemen Ilmu Lingkungan, Universitas Indonesia, Depok, Jakarta. \\ * Corresponding Author: greenhospital12853@gmail.com
}

Info Artikel : Diterima 24 Oktober 2019 ; Disetujui 27 Januari 2020 ; Publikasi 1 April 2020

\begin{abstract}
ABSTRAK
Latar belakang: Pengelolaan lingkungan rumah sakit (RS) secara berkelanjutan menjadi sangat penting dalam rangka meminimalisasi konstribusi negatif terhadap pemanasan global. Tujuan penelitian ini adalah 1) menyusun atribut green hospital di Indonesia, dan 2) menganalisis status keberlanjutan pengelolaan lingkungan RS di Indonesia.

Metode: Penelitian ini menggunakan dua pendekatan yakni pendekatan kualitatif dan kuantitatif. Jenis data yang dikumpulkan merupakan jenis data primer dan data sekunder. Metode pengumpulan data terdiri atas studi pustaka, survei, wawancara mendalam, dan pendapat pakar. Metode analisis data yang digunakan adalah analisis deskriptif dan inferensial dengan pendekatan Multidimensional Scalling (MDS) Rap Green Hospital.

Hasil: Hasil analisis diperoleh, atribut green hospital RS di Indonesia terdiri dari enam dimensi yakni dimensi ekologi, ekonomi, sosial, teknologi, kesehatan lingkungan dan kelembagaan. Keenam dimensi tersebut terdiri dari 42 atribut dan 151 sub atribut. Status keberlanjutan pengelolaan lingkungan RS dalam kategori cukup berkelanjutan (yellow hospital) dengan skor $71.233 \%$. Faktor pengungkit keberlanjutan pengelolaan lingkungan RS meliputi: a) Pengelolaan limbah non medis; b) Pengelolaan limbah B3; c) Lingkungan dalam bangunan; d) Lingkungan Luar bangunan; e) Mitigasi dan adaptasi bencana; f) Sumber dana; g) Kinerja anggaran; h) Budaya ramah lingkungan; i) pengembangan partisipasi masyarakat; j) Tingkat kepuasan; k) Teknologi konservasi energi; 1) Teknologi pengolahan limbah padat, cair dan gas; m) Infeksi nosokomial; n) Fasilitas sanitasi; o) Promosi kesehatan, p) Kepemimpinan; q) Sumberdaya manusia; dan r) Dokumen lingkungan.

Simpulan: Atribut green hospital rumah sakit di Indonesia terdiri atas enam dimensi yakni dimensi ekologi, ekonomi, sosial, teknologi, kesehatan lingkungan dan kelembagaan. Keenam dimensi tersebut terbagi dalam 42 atribut dan 151 sub atribut.
\end{abstract}

Kata kunci: atribut; penilaian; keberlanjutan pengelolaan lingkungan; green hospital

\section{ABSTRACT}

Title: Attribute Assessment of the Sustainability of Hospital Environmental Management Towards Green Hospital in Indonesia

Background: Sustainable management of the hospital environment is very important in order to minimize the negative contribution to global warming. The purpose of this study is 1) to compile the attributes of green hospitals in Indonesia, and 2) to analyze the sustainability status of hospital environmental management in Indonesia.

Methods: This study uses two approaches namely qualitative and quantitative approaches. The type of data collected is a type of primary data and secondary data. Data collection methods consist of study literature, 
surveys, in-depth interviews, and expert judgment. The data analysis method used is descriptive and inferential analysis with the Multidimensional Scaling (MDS) Rap Green Hospital approach.

Results: The analysis results obtained, the attributes of green hospital hospitals in Indonesia consist of six dimensions namely the dimensions of ecology, economics, social, technology, environmental health and institutional. The six dimensions consist of 42 attributes and 151 sub attributes. Status of environmental management of hospitals in the category of sustainable enough (yellow hospital) with a score of $71,233 \%$. Factors for the sustainability of hospital environmental management include: a) Non-medical waste management; b) Hazardous Poison Materials waste management; c) The environment in the building; d) Outside environment of buildings; e) Disaster mitigation and adaptation; f) Sources of funds; g) Budget performance; h) green culture; i) development of community participation; $j$ ) Level of satisfaction; $k$ ) Energy conservation technology; l) Solid, liquid and gas waste treatment technology; m) Nosocomial infections; n) Sanitation facilities; o) Health promotion, p) Leadership; q) Human resources; and r) Environmental documents.

Conclusion: The attributes of green hospital in Indonesia consist of six dimensions, are ecology, economic, social, technology, environmental health, and institutional. The six dimensions are divided into 42 attributes and 151 sub attributes.

Keywords: attribute; assessment; sustainability; environmental management; green hospital

\section{PENDAHULUAN}

Rumah Sakit (RS) merupakan salah satu institusi sekaligus industri penyumbang terjadinya penurunan kualitas lingkungan. Hal ini karena dalam operasionalisasi pelayanan kesehatan, RS mempergunakan alat maupun material berkonstribusi terhadap pencemaran lingkungan ${ }^{1}$. Penggunaan produk berteknologi tinggi, obat-obatan, konstruksi gedung, makanan yang berasal sumberdaya lingkungan sekitar, limbah medis maupun non medis merupakan komponen yang sangat sifnifikan sebagai sumber polutan di dunia.

Di Indonesia, hasil kajian terhadap 100 rumah sakit (RS) di Jawa dan Bali menunjukkan rata-rata produksi sampah sebesar $3,2 \mathrm{~kg} / \mathrm{tempat}$ tidur/hari. Sedangkan produksi limbah cair sebesar 416,8 liter/tempat tidur/hari. Diperkirakan secara nasional, produksi limbah padat rumah sakit sebesar 376.089 ton/hari dan produksi air limbah sebesar $48.985,70$ ton/hari ${ }^{2}$. Besarnya volume limbah padat dan cair yang dihasilkan oleh RS, berpotensi mencemari lingkungan serta menjadi penyebab terjadinya kecelakaan kerja serta penularan penyakit. Oleh karena itu, pengawasan sistem pengolahan limbah RS perlu dioptimalkan agar pelayanan dapat lebih bermutu seiring meningkatnya kebutuhan masyarakat akan pelayanan kesehatan. Pengelolaan sampah medis dan non medis disamping sangat dibutuhkan bagi kenyamanan dan kebersihan RS, juga karena dapat memutuskan mata rantai penyebaran penyakit menular terutama infeksi nosokomial ${ }^{3}$.

Persoalan limbah RS merupakan salah satu dari sekian banyak problem yang ada dalam rangkaian proses pelayanan pada intitusi kesehatan. Kegiatan pengelolaan dalam kerangka efisiensi energi, sumberdaya air, makanan dan minuman, transportasi, pengelolaan farmasi bahkan sampai pada saat pemesanan material kesehatan menjadi fokus yang tidak kalah penting disamping limbah yang dihasilkan ${ }^{4}$. Dampak dari pengelolaan lingkungan yang tidak maksimal dapat berkonstribusi terhadap terjadinya pencemaran tanah, air dan udara di sekitarnya dan infeksi nosokomial di lingkungan kerja ${ }^{5}$. Keadaan demikian sedikit banyak akan menimbulkan hazard (bahaya) terhadap keselamatan baik kepada pasien maupun pekerja Rumah sakit itu sendiri.

Pembangunan kesehatan di Indonesia dimasa mendatang perlu menghadirkan model fasilitas pelayanan kesehatan yang yang tidak hanya berorientasi pada pasien dengan mengedepankan mutu dan keselamatan, tetapi juga berorientasi pada efisiensi dalam penggunaan sumber daya dan perlindungan terhadap mutu lingkungan hidup atau dikenal sebagai green hospital ${ }^{6}$.

Secara umum, konsep green hospital diadopsi dari konsep bangunan hijau, yaitu bangunan dimana dalam perancangan, pembangunan, pengoperasian serta dalam pemeliharaannya memperhatikan aspekaspek lingkungan yang didasarkan pada kaidah pembangunan berkelanjutan ${ }^{6}$. Green Hospital menjadi sebuah alternatif dalam meminimalisasi konstribusi industri RS atas terjadinya pemanasan global. Hal ini dikarenakan pada prinsipnya green hospital bertujuan mengurangi penggunaan sumber daya alam, mengurangi dampak terhadap kerusakan lingkungan dan meningkatkan kualitas udara ruangan menjadi lebih sehat. Seperti telah disebutkan di atas, bahwa keberadaan RS dalam satu kesatuan ekosistem di tengah isu dampak perubahan iklim dan pemanasan global serta degradasi lingkungan, ikut bertanggung jawab atas keberlanjutan kualitas lingkungan dan pemanfaatan sumber daya alam.

Berdasarkan fakta yang telah diuraikan di atas, penelitian ini bertujuan untuk merumuskan atribut green hospital serta penerapannya untuk menilai status keberlanjutan pengelolaan lingkungan rumah sakit di Indonesia. 


\section{MATERI DAN METODE}

Penelitian ini meliputi 2 (dua) pendekatan utama yakni, penelitian kualitatif dimana objek merupakan objek yang alamiah atau objek yang apa adanya dan tidak dimanipulasi dimana peneliti menjadi instrumen yang berinteraksi dengan sumber data melalui direct observation (observasi langsung) dan indepth interview (wawancara mendalam) serta kajian kepustakaan. Pada tujuan kedua, survei dilakukan untuk menilai status keberlanjutan pengelolaan lingkungan RS yang dirancang secara khusus dan disesuaikan dengan kebutuhan penelitian.

Penelitian ini melibatkan narasumber/informan yang didasarkan pada prinsip kesesuaian dan kecukupan. Prinsip kesesuaian memilih informan berdasarkan pengetahuan yang dimiliki dan sesuai dengan topik penelitian. Prinsip kecukupan tidak mensyaratkan jumlah informan melainkan kelengkapan data yang didapatkan.

Jenis data yang dikumpulkan dalam penelitian ini adalah jenis data primer dan data sekunder. Data primer adalah data yang diperoleh secara langsung dari lapangan penelitian, baik berupa pengukuran, pengamatan maupun wawancara ${ }^{7}$. Data sekunder adalah data hasil pengumpulan orang lain dengan maksud tersendiri dan mempunyai kategorisasi atau klasifikasi menurut keperluan ${ }^{8}$. Metode pengumpulan data terdiri atas; studi pustaka, survei, in-depth interview dan expert judgment. Pengumpulan data dalam rangka merumuskan atribut green hospital dilakukan dengan studi kepustakaan terhadap atribut green hospital di negara-negara modern (USA, Ingggris, Australia), negara berkembang khususnya di Asia (Malaysia dan Singapura) dan pendapat pakar.

Pakar dipilih sebanyak 7 (tujuh) narasumber dari berbagai profesi yang meliputi praktisi, akademisi, pembuat kebijakan terkait dan pemerhati perkembangan green hospital di Indonesia. Praktisi antara lain dua orang direktur dan seorang pelaksana pengelolaan kesehatan lingkungan. Responden akademisi sebanyak satu pengajar/dosen bidang kesehatan lingkungan. Responden pembuat kebijakan masing-masing seorang pejabat di jajaran Kemenkes RI dan dua Kemen LHK. Responden pemerhati yang dijadikan responden sebanyak satu mantan direktur rumah sakit Syamsudin SH Sukabumi yang merupakan salah seorang tokoh organisasi internasional Global Green Health Hospital (GGHH).

Pengambilan data dalam rangka pengisian skoring skala good-bad diperkuat dengan data-data sekunder. Pedoman yang digunakan dalam penilaian skala good bad menggunakan Green Hospital Assessment test for Indonesia Hospital (GHATIH) versi 2019 yang menjadi bagian tidak terpisahkan dari penelitian ini. GHATIH versi 2019 berbasis atribut green hospital yang sudah terumuskan sebelumnya..

Analisis data menggunakan proses tranformasi baku (validf) untuk memperoleh sebuah hasil berupa informasi yang dapat menggambarkan data dan menjadi dasar dalam pengambilan keputusan ${ }^{9}$. Metode analisis yang digunakan terdiri atas; 1) metode analisis perbandingan (comparison analysis) yang didasarkan pada studi kepustakaan dan expert judgement, dan 2) metode analisis keberlanjutan yaitu metode MDS (Multidimensional Scaling) dengan berbasis penggunaan software Rapfish. Pendekatan ini didasarkan pada prinsip Multi Criteria Analysis (MCA) dengan mengandalkan algoritma yang disebut sebagai algoritma $\mathrm{MDS}^{10}$. MDS merupakan teknik analisis statistika yang melakukan transformasi multidimensi ${ }^{11}$. Penelitian ini menganalisis tingkat keberlanjutan pengelolaan lingkungan rumah sakit berbasis green hospital dengan menggunakan teknik ordinasi MDS Rapid Appraisal for Green Hospital yang disingkat Rap Green Hospital.

Hasil analisis berupa nilai tingkat keberlanjutan dan atribut pengungkit kepengelolaan lingkungan pada obyek penelitian. Skoring yang diberikan pada setiap atribut akan menentukan posisi keberlanjutan terhadap dua titik acuan (reference) yaitu; good-bad. Penentuan atribut pengungkit keberlanjutan pengelolaan didasarkan pada nilai Root Mean Square (RMS). Nilai RMS menunjukkan besarnya peranan setiap atribut terhadap sensitivitas status keberlanjutan ${ }^{11}$. Salah satu prinsip yang digunakan dalam penentuan atribut pengungkit berdasarkan nilai RMS adalah prinsip pareto optimum. Prinsip Pareto atau juga dikenal sebagai aturan 80/20 menyatakan bahwa untuk banyak kejadian, sekitar $80 \%$ daripada efeknya disebabkan oleh $20 \%$ dari penyebabnya $^{12}$. Pada penelitian ini hasil dari penentuan faktor pengungkit tidak satupun ada atribut yang ekstrim, sehingga paretto optimum merupakan jalan terbaik dalam menentukan faktor-faktor pengungkit keberlanjutan pengelolaan lingkungan rumah sakit di Indonesia.

Penelitian status keberlanjutan pengelolaan lingkungan rumah sakit di Indonesia menggunakan studi kasus di Jakarta dan sekitarnya. Pemilihan sampel rumah sakit didasarkan atas kebutuhan yang pada saat penelitian berlangsung telah mencanangkan penerapan konsep green hospital pada pengelolaan lingkungannya serta bersedia menjadi obyek penelitian. Keempat rumah sakit tersebut adalah Rumah sakit Kanker Dharmais (RSKD), RSUP Persahabatan (RSUPP), Rumkital Dr. Mintohardjo (RSMTH) dan RS Mekarsari Bekasi (RSMS).

\section{HASIL PENELITIAN \\ Perumusan atribut green hospital di Indonesia}

Metode pengambilan data dilakukan dengan studi pustaka, wawancara mendalam pakar dan survei lapangan. Pakar yang terlibat dalam perumusan atribut kriteria green hospital ini sebanyak tujuh orang berasal dari praktisi dua direktur rumah sakit dan masing-masing seorang dari pengelola kesehatan lingkungan di rumah sakit, akademisi bidang terkait, pembuat kebijakan dari Kemenkes RI dan Kemen LHK RI, serta pemerhati manajemen lingkungan 
rumah sakit. Informan penelitian didukung oleh pejabat pelaksana pengelola kesehatan lingkungan dan pihak terkait lainnya di masing-masing rumah sakit.

Atribut dan sub atribut green hospital (Tabel 1 dan 2) yang dihasilkan ini menjadi pedoman dalam penilaian skala good bad pada fase penilaian status keberlanjutan pengelolaan lingkungan rumah sakit dengan skor penilaian setiap atribut dengan skala terburuk (bad) hingga terbaik (good).

Tabel 1. Dimensi dan kriteria green hospital di Indonesia

\begin{tabular}{|c|c|}
\hline Dimensi & Kriteria \\
\hline \multirow[t]{8}{*}{ Lingkungan } & 1. Lingkungan luar bangunan ${ }^{1,2,3,4,5,10,11,12,15}$ \\
\hline & 2. Lingkungan dalam bangunan $1,2,3,4,5,8,9,10,11,12,13,14 ; 15$ \\
\hline & 3. Rokok $^{17}$ \\
\hline & 4. Pengelolaan limbah $b 3^{1,2,3,4,5,7,8,9,11,12,15,16}$ \\
\hline & 5. Pengelolaan limbah non medis $1,2,3,4,5,7,8,9,10,11,12,13,14,15,16$ \\
\hline & 6. Material non medis ${ }^{8,9,15}$ \\
\hline & 7. Material medis ${ }^{9,15,17}$ \\
\hline & 8. Mitigasi dan adaptasi bencana ${ }^{20}$ \\
\hline \multirow[t]{6}{*}{ Ekonomi } & 9. Penghematan air ${ }^{1,2,3,4,5,10,11,12,14}$ \\
\hline & 10. Penghematan energi $1,2,3,4,5,10,11,12,14$ \\
\hline & 11. Sumber dana ${ }^{13,15}$ \\
\hline & 12. Alokasi anggaran ${ }^{13,15}$ \\
\hline & 13. Kinerja dan anggaran ${ }^{13,15}$ \\
\hline & 14. Pemasaran ${ }^{15}$ \\
\hline \multirow[t]{8}{*}{ Sosial } & 15. Pendidikan ramah lingkungan $6,10,11,12$ \\
\hline & 16. Tata kelola Transportasi $\mathrm{i}^{3,8,9,12}$ \\
\hline & 17. Tata Kelola Perparkiran ${ }^{16}$ \\
\hline & 18. Pengembangan partisipasi masyarakat $t^{8,9,11,12}$ \\
\hline & 19. Tingkat Kepuasan ${ }^{12}$ \\
\hline & 20. Aksesibilitas ${ }^{15,16}$ \\
\hline & 21. Budaya (green culture) ${ }^{15,18,19}$ \\
\hline & 22. Fasilitas Publik ${ }^{15,16}$ \\
\hline \multirow[t]{6}{*}{ Teknologi } & 23. Inovasi $i^{2,3,4,5,8,9,10,11,12,13,14}$ \\
\hline & 24. Teknologi pengolahan limbah ${ }^{1,2,3,4,5,8,9,10,11,12,14}$ \\
\hline & 25. Teknologi pengelolaan limbah ${ }^{1,2,3,4,5.6,7,8,9,10,11,12,13,14}$ \\
\hline & 26. Teknologi konservasi energi $i^{1,2,3,4,5,10,11,12,14}$ \\
\hline & 27. Teknologi konservasi air ${ }^{1,2,3,4,5,10,11,12,14}$ \\
\hline & 28. Teknologi Pengelolaan udara bersih $9,18,19$. \\
\hline \multirow[t]{8}{*}{ Kesehatan Lingkungan } & 29. Promosi kesehatan $6,7,8,9,12,13,14$ \\
\hline & 30. Infeksi nosokomial ${ }^{6,7,8,9,12}$ \\
\hline & 31. Makanan dan minuman ${ }^{6,7,8,9,12}$ \\
\hline & 32. Vektor dan binatang pengganggu ${ }^{7,8,9,11,12}$ \\
\hline & 33. Linen $7,8,9,11,12$ \\
\hline & 34. Dekontaminasi ${ }^{9,19}$ \\
\hline & 35. Pengamanan bahaya radiasi $i^{6,7,8,9,10,11,12}$ \\
\hline & 36. Fasilitas sanitasi sanitasi ${ }^{7,8,9,11,12}$ \\
\hline \multirow[t]{6}{*}{ Kelembagaan } & 37. Kepemimpinan (green leadership ${ }^{1,2,3,4,5,6,7,8,9,10,11,12,14}$. \\
\hline & 38. Organisasi 9,19 \\
\hline & 39. Dokumen lingkungan $1,2,3,4,5,6,7,10,11,12$. \\
\hline & 40. $\mathrm{Sdm}^{4,7,10,11,12,15,18,19}$ \\
\hline & 41. Lembaga pengontrol ${ }^{18}$ \\
\hline & 42. Hubungan kolegial ${ }^{10,11,12}$ \\
\hline
\end{tabular}

Keterangan: Nomor: (1) BREEAM (2014)-Inggris; (2)LEED (2009)- Amerika Serikat; ${ }^{(3)}$ GREEN STAR (2009)-Australia; ${ }^{(4)}$ GBIAC for NREB (2014)-Malaysia; (5) GREEN MARK-Singapura; ${ }^{(6)}$ ALPHA 2-Health Promotion Hospital (HPH)-Indonesia; (7) Peraturan Pemerintah RI Nomor 50 tahun 2012; ${ }^{(8)}$ Menteri Kesehatan RI nomor 1405/Menkes/SK/XI/2002; ${ }^{(}{ }^{\circ}$ Kepmenkes RI Nomor 1204/MENKES/KEP/X/2004; ${ }^{(10)}$ Standar Nasional Indonesia (SNI) 14001-2005; ${ }^{(11)}$ Permen LH RI nomor 06 Tahun 2013; (12)Sutoto et.al., (2014); (13) Peraturan Menteri Keuangan RI Nomor 134/PMK.06/2005, ${ }^{(14)}$ Inpres Nomor 12 tahun 2011; ${ }^{(15)}$ UU nomor 44 tahun 2009; (16) GBIC-Greenship 1.0; (17) PP RI nomor 19 tahun 2003; ${ }^{(18)}$ UU nomor 32 tahun 2009; ${ }^{(19)}$ UU nomor 36 tahun 2009; ${ }^{(20)}$ UU nomor 24 tahun 2007. 
Tabel 2. Rekapitulasi atribut green hospital untuk rumah sakit di Indonesia

\begin{tabular}{|c|c|c|}
\hline Dimensi & Atribut & Total \\
\hline Ekologi & $\begin{array}{l}\text { Lingkungan Luar Bangunan (outdoor); Lingkungan Dalam Bangunan } \\
\text { (indoor); Rokok; Pengelolaan Limbah B3; Pengelolaan Limbah Non Medis; } \\
\text { Material Non Medis; Material Medis; Mitigasi dan Adaptasi Bencana }\end{array}$ & 8 \\
\hline Ekonomi & $\begin{array}{l}\text { Penghematan Air; Penghematan Energi; Sumber Dana; Alokasi Anggaran; } \\
\text { Kinerja dan Anggaran; Pemasaran; }\end{array}$ & 6 \\
\hline Sosial & $\begin{array}{l}\text { Pendidikan ramah lingkungan; Tata kelola Transportasi; Tata Kelola } \\
\text { Perparkiran; Budaya; Pengembangan partisipasi masyarakat; Tingkat } \\
\text { Kepuasan; Aksesibilitas; Fasilitas Publik }\end{array}$ & 8 \\
\hline Teknologi & $\begin{array}{l}\text { Inovasi; Teknologi Pengolahan Limbah; Teknologi Pengelolaan Limbah; } \\
\text { Teknologi Konservasi Energi; Teknologi Konservasi Air; Teknologi } \\
\text { Pengelolaan udara bersih; }\end{array}$ & 6 \\
\hline Kesling & $\begin{array}{l}\text { Promosi Kesehatan; Infeksi Nosokomial; Makanan dan Minuman; Vektor } \\
\text { dan Binatang Pengganggu; Linen; Dekontaminasi; Pengamanan Bahaya } \\
\text { Radiasi; Fasilitas Sanitasi }\end{array}$ & 8 \\
\hline Kelembagaan & $\begin{array}{l}\text { Kepemimpinan; Organisasi; Dokumen Lingkungan; SDM; Lembaga } \\
\text { Pengontrol; Hubungan Kolegial. }\end{array}$ & 6 \\
\hline
\end{tabular}

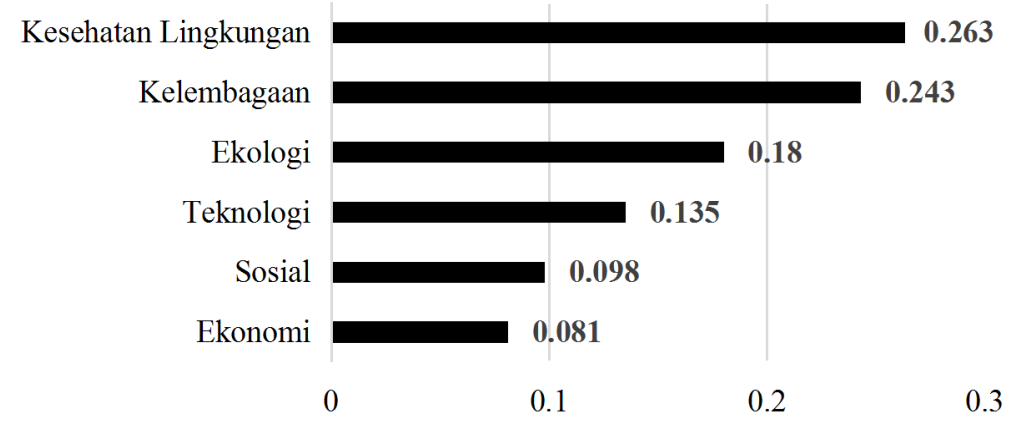

Gambar 1. Hasil pembobotan setiap dimensi menggunakan metode AHP

\section{Penerapan atribut green hospital dalam penilaian keberlanjutan Pengelolaan Lingkungan Rumah Sakit di Indonesia}

Pengelolaan lingkungan rumah sakit memerlukan keterpaduan sektor dan keterpaduan stakehoder. Agar pengelolaan lingkungan rumah sakit menuju green hospital dapat terwujud, maka kajian keenam dimensi pengelolaan sebagai indikator utama keberlanjutan menjadi sangat penting. Penilaian indeks keberlanjutan pada penelitian ini ditentukan berdasarkan nilai bobot setiap dimensi. Hasil pembobotan setiap dimensi didasarkan pada pendapat tujuh pakar dengan metode Analisis Hirarkhi Proses (AHP). Ketujuh pakar tersebut berasal dari praktisi dua direktur rumah sakit dan masing-masing seorang dari pengelola kesehatan lingkungan di rumah sakit, akademisi bidang terkait, pembuat kebijakan dari Kemenkes RI dan Kemen LHK RI, serta pemerhati manajemen lingkungan rumah sakit. Hasil pembobotan dengan menggunakan metode AHP secara berturut-turut dari dari keenam dimensi yaitu: dimensi kesehatan lingkungan (0.263), dimensi kelembagaan (0.243), dimensi ekologi (0.180), dimensi teknologi (0.135), dimensi sosial (0.098) dan dimensi ekonomi (0.081). Secara lebih jelas tersaji pada Gambar 1.

Proses penilaian setiap dimensi di lapangan, dikalikan nilai bobot setiap dimensi. Nilai akhir indek keberlanjutan diperoleh setelah diakumulasi nilai antar dimensi sehingga menjadi nilai indeks keberlanjutan pengelolaan lingkungan sebuah rumah sakit seperti pada Tabel 3. Sedangkan rata-rata nilai keberlanjutan pengelolaan rumah sakit di Jakarta merupakan jumlah keseluruhan nilai akhir indeks keberlanjutan dibagi jumlah rumah sakit obyek penelitian.

Mengacu pada skala yang dikembangkan University Columbia, Canada dalam Fauzi dan Anna (2005) serta Fauzi dan Oxtavianus (2014), yaitu nilai keberlanjutan/tidak berlanjutnya status dari tiap-tiap dimensi yang dianalisis adalah berkisar skor antara 0100, yakni; Skor 0,00-25,00 berarti buruk (tidak berkelanjutan); skor $(25,01-50,00)$ berarti kurang berkelanjutan; skor $(50,01-75,00)$ berarti cukup berkelanjutan dan skor $(75,01-100,00)$ berarti baik status berkelanjutannya. Nilai hasil dari software ini menunjukkan keberlanjutan (green)/tidaknya status 
dari tiap-tiap dimensi yang dianalisis seperti pada Tabel 4.

Penggunaan MDS Rap Green Hospital disamping menghasilkan penilaian status, juga menghasilkan faktor pengungkit atau penentu keberlanjutan pengelolaan lingkungan rumah sakit seperti pada Tabel 5. Adapun trade off berdasarkan dimensi dari keempat rumah sakit tersebut disajikan pada Gambar 2.

Tabel 3. Hasil perhitungan Indeks keberlanjutan multidimensi dengan memperhitungkan pembobotan antar dimensi

\begin{tabular}{lccccccc}
\hline \multicolumn{1}{c}{ RS } & Ekologi & Ekonomi & Sosial & Teknologi & Kesling & Kelembagaan & $\begin{array}{c}\text { Indeks } \\
\text { Keberlanjutan }\end{array}$ \\
\hline RSKD & 15.241 & 6.385 & 8.067 & 12.389 & 22.221 & 22.519 & 86.822 \\
RSUPP & 14.040 & 5.712 & 6.077 & 11.665 & 20.664 & 21.275 & 79.433 \\
RSMS & 15.242 & 4.018 & 4.167 & 6.773 & 13.700 & 17.355 & 61.255 \\
RSMTH & 10.476 & 4.187 & 3.961 & 5.636 & 15.798 & 17.365 & 57.423 \\
\hline Rata-rata & 13.750 & 5.076 & 5.568 & 9.116 & 18.096 & 19.629 & 71.233 \\
\hline
\end{tabular}

Tabel 4. Kriteria Indeks keberlanjutan pengelolaan lingkungan rumah sakit berbasis green hospital.

\begin{tabular}{|c|c|c|}
\hline Kategori & Nilai & Keterangan \\
\hline $\begin{array}{l}\text { Green Hospital } \\
\text { (Berkelanjutan) }\end{array}$ & $75.01-100.00$ & $\begin{array}{l}\text { Upaya dan/atau kegiatan yang telah secara konsisten } \\
\text { menunjukkan keunggulan lingkungan pada proses pelayanan } \\
\text { kesehatan yang beretika dan bertanggung jawab secara } \\
\text { berkelanjutan. }\end{array}$ \\
\hline $\begin{array}{l}\text { Yellow Hospital } \\
\text { (Cukup } \\
\text { Berkelanjutan) }\end{array}$ & $50.01-75.00$ & $\begin{array}{l}\text { Usaha dan/atau kegiatan yang telah sesuai dengan yang } \\
\text { dipersyaratkan melalui pelaksanaan sistem pengelolaan } \\
\text { lingkungan, pemanfaatan sumber daya secara efesien dan } \\
\text { upaya tanggungjawab sosial dengan baik dan cukup } \\
\text { berkelanjutan. }\end{array}$ \\
\hline $\begin{array}{l}\text { Brown Hospital } \\
\text { (Kurang } \\
\text { Berkelanjutan) }\end{array}$ & $25.01-50.00$ & $\begin{array}{l}\text { Usaha dan/atau kegiatan yang telah melakukan usaha } \\
\text { pengelolaan lingkungan yang dipersyaratkan sesuai dengan } \\
\text { ketentuan atau peraturan perundang-undangan. }\end{array}$ \\
\hline $\begin{array}{l}\text { Red Hospital } \\
\text { (Tidak Berkelanjutan) }\end{array}$ & $0.00-25.00$ & $\begin{array}{l}\text { Upaya pengelolaan lingkungan yang dilakukan belum sesuai } \\
\text { dengan persyaratan sebagaimana diatur dalam peraturan } \\
\text { perundang-undangan. }\end{array}$ \\
\hline
\end{tabular}

Tabel 5. Atribut pengungkit pengelolaan lingkungan menuju green hospital

\begin{tabular}{llc}
\hline \multicolumn{1}{c}{ Dimensi } & \multicolumn{1}{c}{ Atribut } & Nilai RMS (\%) \\
\hline Ekologi & Pengelolaan limbah non medis & 2.85 \\
& Pengelolaan limbah B3 & 2.88 \\
& Lingkungan dalam bangunan (indoor) & 3.19 \\
& Lingkungan Luar bangunan (outdoor) & 3.15 \\
Ekonomi & Mitigasi dan adaptasi bencana & 2.66 \\
Sosial & Sumber dana & 7.91 \\
& Kinerja anggaran & 4.76 \\
Teknologi & Budaya (green leadership) & 6.43 \\
\multirow{5}{*}{ Kesehatan Lingkungan } & 6.16 \\
& Tingkat kepuasan & 4.32 \\
& Pengembangan partisipasi masyarakat & 5.53 \\
Kelembagaan & Teknologi konservasi energi & 4.45 \\
& Teknologi pengolahan limbah & 4.85 \\
& Fasilitas sanitasi & 3.65 \\
& Promosi kesehatan & 3.18 \\
& Kepemimpinan & 5.34 \\
& Sumberdaya manusia & 4.19 \\
& Dokumen lingkungan & 4.57 \\
\hline
\end{tabular}




\section{TRADE OFF KEBERLANJUTAN PENGELOLAAN LINGKUNGAN RS BERBASIS GREEN HOSPITAL}

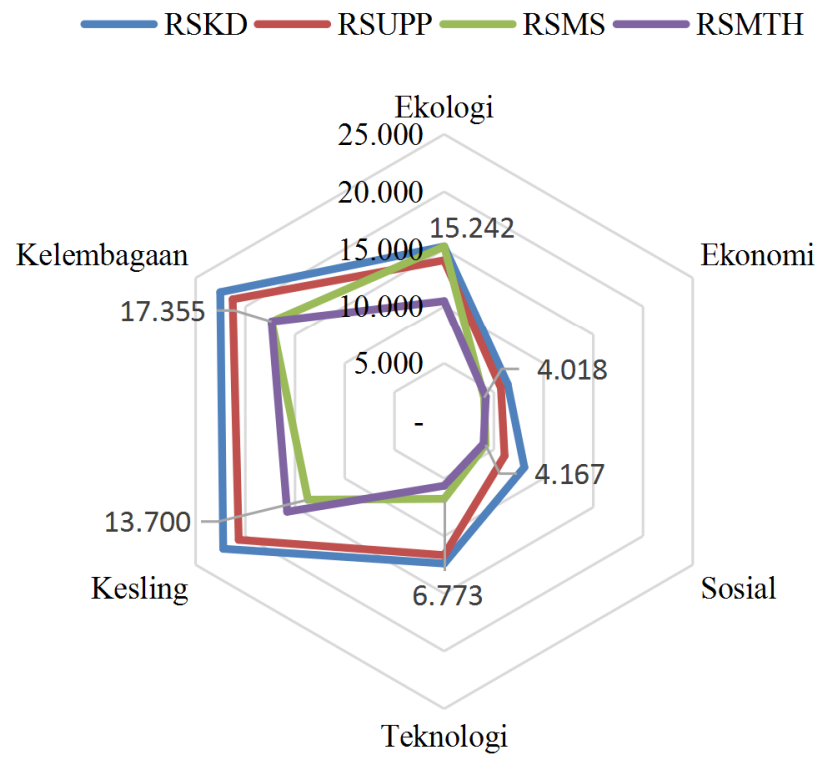

Gambar 2. Status keberlanjutan pengelolaan lingkungan rumah sakit di Indonesia

\section{PEMBAHASAN}

\section{Perumusan atribut green hospital di Indonesia}

Konsep Sustainable Development Goals (SDGs)

sebagai agenda pembangunan terkini, mengakomodasi perubahan situasi dunia terkait isu penipisan sumberdaya alam, kerusakan lingkungan, perubahan iklim, perlindungan sosial, ketahanan pangan dan energi dan pembangunan yang berpihak pada rakyat miskin. Rumah sakit sebagai salah satu industri pengguna sumberdaya alam baik energi, air, sumber makanan sekaligus pembuang limbah non medis maupun medis berbahaya memerlukan penanganan secara khusus dan berkelanjutan. Berdasarkan hasil penelitian konsep atribut green hospital di Indonesia terdiri dari enam dimensi yakni ekologi, ekonomi, social, teknologi, kesehatan lingkungan dan kelembagaan. Secara lebih rinci sebagai berikut:

\section{Dimensi ekologi}

Dimensi ekologi teridiri dari 8 (delapan) atribut, pertama adalah atribut lingkungan luar bangunan (outdoor). Atribut ini terdiri dari 5 sub atribut yakni; lanskap ruang terbuka hijau, fasilitas konservasi air, limpasan air hujan, taman penyembuhan (healing garden) dan tempat penyemaian, perawatan dan pengembangan tanamtanaman (nursery) untuk kebutuhan rumah sakit. Atribut kedua adalah lingkungan dalam bangunan (indoor) yang terdiri dari 8 (delapan) sub atribut yakni; konstruksi bangunan rumah sakit, minimalisasi urban heat island effect, introduksi udara luar (penghawaan), polutan mikroba, polutan fisik dan kimia di udara, kenyamanan visual, tingkat kebisingan, pencahayaan dan zonasi resiko. Atribut ketiga adalah rokok, rokok merupakan atribut yang memberikan penekanan pada implementasi kawasan yang bebas dari asap rokok.
Hal ini diartikan bahwa dalam lingkungan rumah sakit sama sekali tidak ada toleransi terhadap aktivitas merokok. Atribut keempat adalah pengelolaan limbah B3 yang terdiri dari 11 sub atribut yaitu; kebijakan, perencanaan pengelolaan limbah B3, pencatatan volume, pengemasan, penyimpanan, pengangkutan, emisi dari tata kelola limbah B3, efluen limbah B3, standar mutu pemanfaatan produk limbah, kriteria jumlah yang dikelola sesuai peraturan serta evaluasi dan pelaporan. Disamping limbah B3, atribut kelima adalah pengelolaan limbah non medis yang terdiri dari 6 (enam) sub atribut yakni; terkait kebijakan, perencanaan, pelaksanaan, evaluasi dan pelaporan terhadap pengelolaan limbah non medis/limbah rumah tangga.

Pengelolaan lingkungan rumah sakit yang ramah lingkungan tidak cukup dengan hanya memahami hilirnya semata, namun juga sangat penting mengetahui bagian hulunya. Selain itu, pengelolaan lingkungan rumah sakit tidak hanya fokus pada out put dari kegiatan berupa limbah, namun juga pada input yakni material yang digunakan, baik medis maupun non medis. Atribut material medis maupun non medis terdiri dari sub atribut kebijakan pengadaan material medis/non medis ramah lingkungan, penerimaan material/bahan, pendistribusian, penyimpanan penggunaan atau pemanfaatan serta disposal atau penghapusan.

Atribut mitigasi dan adaptasi bencana ditujukan agar rumah sakit memiliki kesiapsiagaan menghadapi berbagai macam bencana tidak terduga, sehingga mampu meminimalisasi terjadinya korban atau kerugian. Sub atribut terdiri dari 3 (tiga) yakni; mitigasi dan adaptasi terhadap bencana banjir, kebakaran dan bahaya lainnya. 
Secara keseluruhan dimensi ekologi terdiri 44 (empat puluh empat) sub atribut. Atribut ini terutama merujuk pada Greenship yang dikeluarkan oleh Green Building Council Indonesia (GBCI), peraturan perundangan dan beberapa penelitian terdahulu.

\section{Dimensi Ekonomi}

Dimensi ekonomi terdiri dari 6 (enam) atribut antara lain; atribut penghematan air, energi, sumber dana, alokasi anggaran, kinerja dan anggaran serta atribut pemasaran. Atribut penghematan air dan energi memiliki sub atribut yang hampir sama yakni terkait organisasi pengelolaan, program konservasi, sosialisasi program penghematan, audit baik air maupun energi dan penggunaan sumber air maupun energi alternantif terbarukan.

Atribut sumber dana meliputi atribut kemandirian yang didukung oleh kebijakan pimpinan rumah sakit dalam upaya penggalangan dana. Disamping hal tersebut, ketersediaan dan kecukupan anggaran sangat tergantung pada kemampuan finansial rumah sakit. Namun demikian penilaian kinerja dalam pengelolaan lingkungan harus tetap berbasiskan pada anggaran. Terkait dengan atribut pemasaran, lebih dititikberatkan pada penelitian yang terfokus pada seberapa besar potensi konstribusi konsep green hospital dalam peningkatan citra dan pangsa pasar rumah sakit. Secara keseluruhan terbagi dalam 15 (lima belas) sub atribut.

\section{Dimensi Sosial}

Penilaian kriteria green hospital ditinjau dari dimensi sosial meliputi 8 (delapan) atribut yakni pendidikan ramah lingkungan, tata kelola transportasi, tata kelola perparkiran, pengembangan partisipasi masyarakat, tingkat kepuasan, aksesibilitas, budaya (green culture) dan fasilitas publik. Secara keseluruhan terbagi dalam 26 (dua puluh enam) sub atribut.

Atribut pendidikan ramah lingkungan memberikan penilaian terhadap program sosialisasi pendidikan ramah lingkungan dan terhadap keberadaan fasilitas penyebaran informasi. Hal ini ditujukan agar dapat diketahui seberapa jauh upaya program green hospital ini diketahui oleh pemangku kepentingan rumah sakit khususnya para karyawan dengan segala fasilitas pendukungnya.

Transportasi, aksesibilitas dan tata kelola perparkiran juga menjadi hal yang sangat penting guna meningkatkan keberlanjutan pelayanan di rumah sakit. Penggunaan alat transportasi berbahan bakar non fosil atau ramah lingkungan mendapat prioritas. Tata kelola perparkiran meliputi kapasitas, alur lalulintas dan informasi pengamanan kendaraan. Sedangkan aksesibilitas terkait dengan kemudahan masuk serta keterjangkauan area rumah sakit.

Tingkat kepuasan baik karyawan, pasien/pengguna layanan dan masyarakat sekitar rumah sakit terhadap layanan pengelolaan lingkungan juga menjadi hal yang penting dalam rangka keberlanjutan pengelolaan program. Program ini sebagai kelanjutan dari program pengembangan partisipasi masyarakat.

Selain itu, hal lain yang juga penting dalam penilaian kriteria green hospital adalah kebersihan, kerapian, keindahan/estetika serta kenyamanan terhadap keberadaan fasilitas publik yang ada. Fasilitas tersebut adalah kantin ramah lingkungan, tempat penitipan anak, fasilitas olahraga dan rekreasi serta ruang tunggu pasien.

\section{Dimensi Teknologi}

Dimensi teknologi pada penyusunan kriteria green hospital ini mencakup inovasi, teknologi pengolahan dan pengelolaan limbah, teknologi konservasi energi dan air serta teknologi pengelolaan udara bersih. Keenam atribut ini berhubungan dengan sistem pengelolaan lingkungan di rumah sakit.

Atribut inovasi meliputi sub atribut inovasi dalam desain dan inovasi pada program-program penghijauan. Sedangkan atribut teknologi pengolahan limbah meliputi teknologi pengolahan limbah padat dan cair. Teknologi pengelolaan limbah meliputi penggunaan kembali (reuse), (recycling), pengolahan menjadi bentuk lain yang lebih bermanfaat) dan pengurangan limbah (reduce) sejak dari hulu dimulainya kegiatan.

Teknologi konservasi energi terkait penelitian pengembangan energi terbarukan, peningkatan pengelolaan sistem pendingin, green power dan metering. Teknologi konservasi air meliputi penelitian pengembangan konservasi air, pemanfaatan hasil pengolahan air limbah, pembangunan sumur resapan, sistem perpipaan hemat air, daur ulang air limbah, produksi air dan metering. Teknologi pengelolaan udara bersih terdiri dari sistem ventilasi adara dan pengelolaan pencemaran udara. Secara keseluruhan terdiri dari 19 (sembilan belas) sub atribut.

\section{Dimensi Kesehatan Lingkungan}

Atribut pada dimensi kesehatan lingkungan terdiri dari 8 (delapan) atribut atau elemen. Atribut tersebut meliputi promosi kesehatan, infeksi nosokomial, makanan dan minuman, vektor dan binatang pengganggu, linen, dekontaminasi, pengamanan bahaya radiasi dan fasilitas sanitasi. Atribut promosi kesehatan (Promkes) pada konteks ini berbasiskan ramah lingkungan berkelanjutan. Selain menilai program-program promkes berbasis ramah lingkungan juga terkait organisasi dan pengawakan penyuluhan kesehatan rumah sakit yang ada. Atribut infeksi nosokomial terdiri dari keorganisasian, program pengendalian dan surveilans infeksi nosokomial. Infeksi nosokomial adalah kejadian infeksi yang menyerang manusia akibat paparan bibit penyakit dari kegiatan di rumah sakit.

Penilaian atribut makanan dan minuman terdiri dari pengawasan bahan makanan dan minuman, sanitasi ruang produksi (dapur dan alat makan), penjamah makanan, penyajian makanan, penyediaan air minum dan optmalisasi penyediaan makanan dan minuman dengan memanfaatkan sumberdaya alam lokal. Penilaian atribut vektor dan binatang 
pengganggu terdiri dari program pemberantasan vektor dan pengendalian binatang pengganggu seperti kucing, tikus dan lain-lain. Seberapa jauh program kegiatan dijalan menjadi faktor penilaian pada atribut ini. Atribut linen terdiri dari tata kelola linen dan bahan pencucian (sabun dan perlengkapan lainnya) ramah lingkungan. kegiatan tata kelola linen dimulai dari penerimaan linen kotor, pelaksanaan pencucian sampai dengan serah terima linen bersih.

Atribut dekontaminasi diartikan sebagai penurunan kontaminan (zat) yang mampu membuat bahan atau alat rentan sebagai penimbul masalah. Atribut ini terdiri dari desinfeksi dan sterilisasi serta program penganggulangannya. Secara keseluruhan terbagi dalam 30 (tiga puluh) sub atribut.

\section{Dimensi Kelembagaan}

Dimensi kelembagaan terdiri dari 6 (enam) atribut antara lain kepemimpinan ramah lingkungan berkelanjutan (green leadership), organisasi, dokumen lingkungan, sumberdaya manusia, lembaga kontrol dan hubungan kolegial. Secara keseluruhan terbagi dalam 17 (tujuh belas) sub atribut.

Atribut kepemimpinan berwawasan lingkungan berkelanjutan (green leadership) terdiri dari komitmen, ketauladanan dan produk kebijakan berbasis ramah lingkungan berkelanjutan. Seorang pemimpin harus memiliki jiwa ketauladanan dalam segala bidang kehidupan, menjadi panutan dan rol model di tengah masyarakat. Pemimpin harus memiliki komitmen yang kuat dimana dalam tindakan dan kebijakannnya berbasis untuk kepentingan orang banyak. Atribut dokumen lingkungan meliputi sub atribut perijinan AMDAL/DPLH, penilaian Proper dari Kementerian LHK, status akreditasi rumah sakit, ijin pembuangan air limbah, perijinan tempat pembuangan sementara, ijin operasional insinerator atau MoU dengan pihak ketiga dalam pengangkutan dan atau pengolahan limbah B3. Keseluruhan dokumen diarsipkan secara cermat dan dipantau terhadap masa keberlakuannya. Atribut organisasi sangat berhubungan dengan artibut kepemimpinan, karena organisasi merupakan kendaraan pimpinan dalam rangka mencapai program dan tujuannya. Hal ini menempatkan posisi pemimpin rumah sakit menjadi sangat sentral dalam implementasi kebijakan khususnya green hospital. Dalam rangka implementasi konsep green hospital, aspek yang dinilai adalah kesolidan organisasi pengelola permasalahan kesehatan lingkungan dan organisasi percepatan menuju green hospital, yakni the green team atau sejenisnya.

Aspek sumberdaya manusia dan budaya kerja di rumah sakit dua hal yang sangat penting. Aktor utama pada kegiatan ini adalah anggota unit/bagian kesehatan lingkungan yang didukung oleh pemangku kepentingan terhadap kehadiran rumah sakit. Budaya kerja berwawasan lingkungan kedepan menjadi sangat penting di tengah isu pemanasan global yang semakin mengkhawatirkan. Budaya kerja ramah lingkungan dalam hal ini diimplementasikan pada penerapan kebiasaan karyawan di segala lapisan pelayanan kesehatan berbasiskan ramah lingkungan seperti kebiasaan cuci tangan sebelum beraktifitas, tidak membuang sampah sembarangan, tidak merokok, budaya hidup bersih dan lain-lain. Sedangkan atribut hubungan kolegial menitikberatkan pada terjalinnya hubungan antar pemerhati dan praktisi kesehatan lingkungan rumah sakit seluas mungkin. Hal ini ditujukan agar antara pelaku di masing-masing rumah sakit akan selalu berhubungan dan berdiskusi dalam rangka pengembangan penerapan konsep green hospital di masing-masing rumah sakit.

\section{Penerapan atribut green hospital dalam penilaian keberlanjutan Pengelolaan Lingkungan Rumah Sakit di Indonesia}

Hasil analisis Rap Green Hospital secara umum menunjukkan nilai indeks keberlanjutan pengelolaan rumah sakit berbasis green hospital di Indonesia dengan studi kasus rumah sakit di Jakarta dan sekitarnya adalah 71.233 atau dikategorikan cukup berkelanjutan (yellow). RSKD merupakan rumah sakit dengan nilai indeks keberlanjutan tertinggi yaitu 86.822 atau dikategorikan berkelanjutan (green hospital). Kondisi yang hampir sama juga terjadi pada RSUPP dengan indeks keberlanjutan 79.433 atau dikategorikan berkelanjutan (green hospital). Sementara RSMK memiliki indeks keberlanjutan 61.255 atau dikategorikan cukup berkelanjutan (yellow hospital). Demikian juga RSMTH memperoleh indeks keberlanjutan sebesar 57.423 atau dikategorikan cukup berkelanjutan (yellow hospital).

Hasil analisis Rap Green Hospital berdasarkan bobot penilaian, ditemukan hal yang menarik yakni nilai kelembagaan (19.629) lebih tinggi dari nilai kesehatan lingkungan (18.096). padahal nilai bobot kesehatan lingkungan (0.263) lebih tinggi dari nilai bobot kelembagaan (0.243). Hal ini terjadi karena faktual di lapangan atribut dimensi kelembagaan ratarata lebih tinggi. Fenomena ini sangat dimungkinkan karena dalam penilaian, proporsi aspek administratif lebih banyak daripada aspek operasional/praktis. Sebaliknya pada dimensi kesehatan lingkungan, aspek operasional lebih banyak daripada aspek administrasinya. Pada umumnya implementasi kegiatan administrasi lebih mudah dikerjakan daripada pekerjaan bersifat operasional atau praktis. Atribut dimensi kelembagaan tersebut antara lain terkait dokumen lingkungan, green leadership, SDM, lembaga kontrol dan hubungan kolegial.

Perbandingan rata-rata antar dimensi lainnya sejalan dengan nilai bobot yang ditentukan pakar pada masing-masing dimensi. Secara berturut-turut setelah dimensi kelembagaan dan kesehatan lingkungan adalah dimensi ekologi, teknologi, sosial, dan ekonomi.

Total indeks/status keberlanjutan sebesar 71.233 merupakan nilai indeks keberlanjutan pengelolaan rumah sakit di Jakarta. Guna melihat trade off 
berdasarkan dimensi dari keempat rumah sakit tersebut disajikan pada Gambar 2.

Berdasarkan Gambar 2, keempat rumah sakit dimensi kelembagaan memperoleh nilai paling tinggi dibandingkan dengan yang lain. Hal ini menunjukkan bahwa secara kelembagaan keempat rumah sakit telah membangun infrastruktur organisasi secara legal, penyiapan sumberdaya manusia pejabat organisasi sekaligus pelaku penerapan konsep green hospital maupun para pendukung lainnya. Green leadership, dokumen lingkungan dan hubungan kolegial pengawak organisasi dengan rekanan di rumah sakit lain sangat erat dan intensif dilakukan dalam rangka memajukan pengelolaaan lingkungan rumah sakit. Dengan demikian dapat diambil konklusi bahwa kondisi saat ini dimensi kelembagaan sangat penting dalam penerapan konsep green hospital di Indonesia.

Dimensi kesehatan lingkungan berada pada urutan kedua, walaupun menurut pakar memiliki bobot paling tinggi. Hal ini masih sejalan dengan kebijakan pemerintah yang telah menerbitkan Peraturan Pemerintah (PP) nomor 7 tahun 2019 tentang kesehatan lingkungan rumah sakit. PP tersebut mengamanahkan bahwa kesehatan lingkungan merupakan aspek penting bersama dengan aspek atau dimensi berpengaruh lainnya seperti ekologi, ekonomi, sosial dan kelembagaan. Dimensi kesehatan lingkungan meliputi atribut promosi kesehatan, infeksi nosokomial, makanan dan minuman, vektor dan binatang pengganggu, linen, dekontaminasi, pengamanan bahaya radiasi dan fasilitas sanitasi.

\section{Atribut Pengungkit Keberlanjutan Pengelolaan Lingkungan Rumah Sakit di Indonesia}

Berdasarkan hasil analisis leverage attribute diperoleh delapan belas atribut pengungkit keberlanjutan dari setiap dimensi pengelolaan, meliputi; dimensi ekologi 5 (lima) atribut, dimensi ekonomi 2 (dua), dimensi sosial 3 (tiga), dimensi teknologi 2 (dua), dimensi kesehatan lingkungan 3 (tiga) dan dimensi kelembagaan 3 (tiga) atribut. Lebih rinci seperti pada Tabel 5.

Berdasarkan hasil analisis leverage attribute diperoleh nilai RMS tertinggi adalah sumber dana (dimensi ekonomi). Sumber dana menjadi pengungkit terhadap aribut-atribut yang lain sehingga perlu mendapat perhatian dari pengelola atau pemilik rumah sakit. Keberadaan sumber dana yang memadai dan berkelanjutan sangat berpengaruh terhadap keberhasilan dan keberlanjutan program-program lainnya. Atribut berikutnya yang memiliki nilai RMS relatif tinggi dibandingkan dengan lainnya adalah Budaya (dimensi sosial).

Budaya organisasi adalah norma, keyakinan, sikap dan filosofi organisasi. Budaya adalah suatu sistem nilai, keyakinan dan norma-norma yang unik yang dimiliki secara bersama oleh anggota suatu organisasi ${ }^{14}$. Budaya juga menjadi suatu penyebab penting bagi keefektifan organisasi rumah sakit. Budaya organisasi mengacu ke sistem makna bersama yang dianut oleh anggota rumah sakit yang membedakan dengan organisasi-organisasi lain.

Budaya dalam konteks pengelolaan lingkungan dimaknai sebagai budaya ramah lingkungan yang berkelanjutan atau green culture. Ketika sistem makna seluruh karyawan rumah sakit memiliki visi dan misi yang sama dalam pengelolaan lingkungan, diyakini percepatan implementasi konsep green hospital akan lebih cepat tercapai. Hal demikian perlu dukungan faktor-faktor pengungkit lainnya seperti kepuasan pengguna layanan maupun karyawan terhadap pengelolaan lingkungan yang selama ini belum pernah dilaksanakan dan dukungan kepemimpinan.

Dukungan kepemimpinan dimaksud adalah realitas dimana setiap kebijakan berbasiskan pada kepentingan pelestarian lingkungan atau green leadership. Implementasi green leadership di rumah sakit diterapkan pada semua level kepemimpinan dari kepala atau direktur rumah sakit sampai karyawan terbawah. Keseluruhan karyawan memiliki kepentingan yang sama dalam penerapan green hospital. demikian juga dengan faktor-faktor pengungkit lainnya, memiliki peran yang menentukan dan harus menjadi perhatian para pimpinan rumah sakit.

Faktor pengungkit berpengaruh terhadap keberhasilan penerapan green hospital, namun demikian dimensi maupun atribut lain tidak boleh ditinggalan. Intervensi kebijakan diberikan guna mempengaruhi perubahan keseluruhan elemen kriteria $^{15}$.

\section{SIMPULAN}

Atribut green hospital rumah sakit di Indonesia terdiri dari enam dimensi yakni dimensi ekologi, ekonomi, sosial, teknologi, kesehatan lingkungan dan kelembagaan. Keenam dimensi tersebut terdiri dari 42 atribut dan 151 sub atribut. Status keberlanjutan pengelolaan lingkungan dalam katagori cukup berkelanjutan (yellow hospital) dengan skor $71.233 \%$. Faktor pengungkit keberlanjutan pengelolaan lingkungan rumah sakit berbasis green hospital di Indonesia, meliputi: a) Pengelolaan limbah non medis, b) Pengelolaan limbah B3, c) Lingkungan dalam bangunan (indoor), d) Lingkungan Luar bangunan (outdoor), e) Mitigasi dan adaptasi bencana, f) Sumber dana, g) Kinerja anggaran h) Budaya (green culture), i) Tingkat kepuasan, j) Pengembangan partisipasi masyarakat, k) Teknologi konservasi energi, 1) Teknologi pengolahan limbah, m) Infeksi nosokomial, n) Fasilitas sanitasi, o) Promosi kesehatan, p) Kepemimpinan q) Sumberdaya manusia dan $r$ ) Dokumen lingkungan. Hasil penilaian status keberlanjutan pengelolaan lingkungan menjadi ukuran sejauh mana keberhasilan pelaksanaan program green hospital pada sebuah rumah sakit di Indonesia. Direkomendasikan untuk dilakukan penelitian lebih jauh terkait model pengelolaan lingkungan rumah sakit menuju green hospital, aplikasi kebijakan maupun inovasi-inovasi lain sehingga mendorong 
percepatan implementasi program di seluruh rumah sakit di Indonesia.

\section{UCAPAN TERIMA KASIH}

Ucapan terima kasih kepada Dr. Ir. Eka Intan Kumala Putri, M.Si, Prof. Dr. Ir. Bambang Pramudya Nurochmat, M.Eng, Dr. Suyud Warno Utomo, M.Si selaku pembimbing materi dan para direktur rumah sakit serta rekan sejawat yang telah berkonstribusi dalam penyelesaian riset ini.

\section{DAFTAR PUSTAKA}

1. Hasibuan H. Tinjauan Yuridis Terhadap Pengelolaan Limbah Bahan Berbahaya dan Beracun (B3) di Rumah Sakit Umum Pusat H. Adam Malik Medan. Yogyakarta. Universitas Islam Indonesia. 2009.

2. Agustina A, Purnama SG. Kajian Pengelolaan Limbah Rumah sakit RSU Provinsi Nusa Tenggara Barat. Community Health. 2014; 2(1): $12-20$.

3. Risnawati F, Purwanto, Setiani O. Penerapan Green Hospital Sebagai Upaya. Manajemen Lingkungan di Rumah Sakit Pertamina Cirebon. Jurnal EKOSAINS. 2015; 7(1): 26-39

4. Alatas H, Ayuningtyas D. Implementasi Green Hospital di RSUD R. Syamsudin, SH dengan Kriteria Kerangka Kinerja Ekselen Malcolm Baldrige. Jurnal ARSI. 2019; 5(2): 85-96.

5. Cahyono B. Model pengelolaan lingkungan pada industri kecil menengah (IKM) di kota Semarang. EKOBIS. 2011; 12 (2): 122-137.

6. Sutoto, Partakusuma, Nasir M, Handayani M. Pengantar green hospital menuju rumah sakit hijau, asri dan efisien. Jakarta. Perhipunan Rumah Sakit Seluruh Indonesia (PERSI). 2014.

7. Nazir M. Metode Penelitian. Jakarta. Ghalia Indonesia. 2003.

8. Nasution S. Metode Penelitian NaturalistikKualitatif. Bandung. Tarsito. 2011.

9. Yusuf M, Daris L. Analisis Data Penelitian; Teori dan Aplikasi dalam Bidang Perikanan. Bogor. IPB Press. 2018. 218 p.

10. Pitcher TJ. Rapfish: A Rapid Appraisal Technique For Fisheries. And Its Application To The Code Of Conduct For Responsible Fisheries. Rome. FAO Fisheries Circular.1999. 47 p.

11. Fauzi A, Oxtavianus A. The Measurement of Sustainable Development in Indonesia. Jurnal Ekonomi Pembangunan : Kajian Masalah Ekonomi dan Pembangunan. 2014, 15 (1): 68-83.

12. Joshi A, Kadam P. An Application of Pareto Analysis And Cause Effect Diagram For Minimization Of Defects In Manual Casting Process. International Journal Of Mechanical And Production Engineering 2014, 2 (2): 36-40

13. Sofiyanurriyanti. Implementasi Proses Bisnis Dalam Upaya Penerapan Green Hospital. Jurnal Teknik Industri 2017, 18 (2); 149-158.

14. Azar FE, Farzianpour F., Foroushani A.R., Badpa M, Azmal M. Evaluation of Green Hospital Dimensions in Teaching and Private Hospitals Covered by Tehran University of Medical Sciences. Journal of Service Science and Management 2015, 8 (8): 259-266.

15. Loumer SH. An Evaluation of Green Building Components \& Their Relationship with Sustainable Development Objects. World Journal of Management and Art 2015, 2 (2): 74-79. 